\title{
Police Charging Decisions in Child Maltreatment Investigations: Findings from the 2008 Ontario Incidence Study of Reported Child Abuse and Neglect
}

\author{
Philip Baiden ${ }^{\mathrm{a}}$, Barbara Fallon ${ }^{\mathrm{a}}$, Wendy den Dunnen ${ }^{\mathrm{b}}$, and Tara Black ${ }^{\mathrm{a}}$ \\ aUniversity of Toronto, Factor-Inwentash Faculty of Social Work, Toronto, Ontario, Canada; ' University \\ of Ottawa, School of Psychology, Ottawa, Ontario, Canada
}

\begin{abstract}
The objective of this study is to use logistic regression to examine factors that influence charging decisions by the police during child maltreatment investigations. An estimated 4,808 substantiated child maltreatment investigations that involved police were obtained from the 2008 Ontario Incidence Study of Reported Child Abuse and Neglect. Of the 4,808 cases examined, police laid charges in about one-third of the cases. Controlling for all other factors, police were 1.6 times more likely to lay charges in physical abuse cases and 2.5 times more likely to lay charges in sexual abuse cases. Other factors associated with police charging decisions include: older victim, cases with multiple types of maltreatment, cases opened for ongoing services, and cases of the child is-living in a house known to have drugs or household hazards. The article discusses the results and their implications for child welfare policy and practice.
\end{abstract}

\section{ARTICLE HISTORY}

Received 26 September 2016 Revised xxxx

Accepted 17 November 2016

\section{KEYWORDS}

child maltreatment; child welfare; police; charging decisions; investigations

In Ontario, Canada, nearly 130,000 children are investigated by child protective services (CPS) each year (Browne et al., 2010). If the concerns are serious, police can be involved in maltreatment investigations to determine whether there is enough evidence (that is, reasonable or probable grounds that a crime took place) in order to lay charges against the perpetrator (Community Legal Education Ontario [CLEO], 2013). However, it is surprising that no study has been conducted within Canada examining what factors might influence police decisions to lay charges during child maltreatment investigations.

Studies that examined police charging decisions in general have observed that to a large extent, decisions by police to lay charges go beyond the legal characteristics of the case (Spears \& Spohn, 1997; Spohn, Beichner, \& DavisFrenzel, 2001). With respect to CPS investigations, such decisions could be influenced by other factors, such as demographic characteristics of the child and the caregiver; the relationship of the alleged perpetrator to the child; and the frequency, severity, and type of maltreatment, in addition to case 
characteristics (Cross, De Vos, \& Whitcomb, 1994; Hartley, Mullings, \& Marquart, 2013; Jones, Finkelhor, \& Halter, 2006; Pipe et al., 2013; Sedlak et al., 2005; Tjaden \& Thoennes, 1992; Walsh et al., 2010).

Estimates of charging incidence vary from study to study. Walsh et al. (2010) examined police decisions to file charges and the likelihood of securing conviction using data from the Dallas Children's Advocacy Center and found that of the 329 cases, police laid charges in $64 \%$ of the cases. Faller and Henry (2000) also examined 323 child sexual abuse cases from 1988 to 1998 in southwest Michigan, United States, and found that police laid charges in $69 \%$ of the cases. However, Tjaden and Thoennes (1992) examined data on 833 child maltreatment substantiated cases from CPS agencies across three counties in the United States and found that charges were laid in $21 \%$ of the cases. The discrepancy in charging incidence rates could be due to differences in the populations examined and the time of data collection. For example, the type of maltreatment investigated (e.g., exposure to intimate partner violence, physical abuse, sexual abuse, neglect, or emotional abuse) could contribute to differing results. Walsh et al (2010) and Faller and Henry (2000) both examined charging rates among sexual abuse cases, while Tjaden and Thoennes (1992) examined charging rates among child maltreatment cases more broadly. In addition, Tjaden and Thoenes (1992) also examined data collected in the mid-1980s, a time when there was less awareness of maltreatment and support for victims.

\section{Factors influencing charging decisions}

A comprehensive review of the extant literature indicates that most of the existing studies in this field of enquiry tend to focus on child sexual abuse cases (Brewer et al., 1997; Connolly \& Read, 2007; Cross et al., 1994; Faller \& Henry, 2000; Finkelhor, 1983; Walsh et al., 2010). Hartley et al. (2013) examined factors impacting the prosecution of child abuse and neglect cases using data from the Children Advocacy Center (CAC) and found that compared to other types of maltreatment, substantiated sexual abuse cases were 7.5 times more likely to be accepted for prosecution.

Findings regarding the association between demographic characteristics of the child (e.g., age and gender) and case prosecution are mixed. For example, some studies (Cross et al., 1994; Finkelhor, 1983; Stroud, Martens, \& Barker, 2000; Tjaden \& Thoennes, 1992; Walsh et al., 2010) have found that older children were significantly more likely than younger children to have their cases prosecuted. In contrast, Brewer et al. (1997) found that children age 13 to 18 year were significantly more likely than their counterparts age 7 to 12 years to have their cases prosecuted. MacMurray (1989) and Sedlak et al. (1996) in their respective studies failed to observe any significant effect of age on the decision to prosecute a case. 
With respect to victim's gender, Hartley et al. (2013) found that police were two times more likely to prosecute maltreatment cases involving female victims than in cases involving male victims. Sedlak et al. (2005) also found that adjusting for maltreatment type, cases pertaining to female victims were more likely to be charged than cases involving male victims. Similar findings have also been reported by other studies (Pipe et al., 2013; Stroud et al., 2000; Walsh et al., 2010). However, some studies failed to find any significant association between victim's gender and maltreatment cases accepted for criminal investigations (Cross et al., 2015) or accepted for prosecution (Brewer et al., 1997).

Studies have found that police are more likely to lay charges in sexual abuse cases involving a male perpetrator (Cross et al., 1994; Pipe et al., 2013; Stroud et al., 2000). Sexual abuse cases are less likely to be prosecuted when the alleged perpetrator had a familial relationship with the child (Brewer et al., 1997; Chapman \& Smith, 1987; Cross et al., 1994; Finkelhor, 1983; Tjaden \& Thoennes, 1992). A recent study by Pipe and her colleagues (2013) found that alleged perpetrators were 1.66 times more likely be charged when she or he was not an immediate family member compared to cases where the alleged perpetrator was an immediate family member. Children and adolescents may be more motivated to deny or recant abuse allegations to protect someone they know, particularly for caregivers upon whom they are dependent. Also, children and adolescents may be less likely to provide information in cases where the perpetrator is familial because they have been pressured to remain silent (Paine \& Hansen, 2002). Furthermore, Pipe and her colleagues found that more than $60 \%$ of sexual abuse cases involving severe abuse, such as penetration, perpetrators were more likely to be charged compared to $40 \%$ of cases involving less severe sexual abuse such as touching and exposure. This finding may be due to the fact that it is more likely to obtain physical evidence of sexual penetration than physical evidence of touching or exposure.

Walsh et al. (2010) also examined the importance of evidence in prosecuting child sexual abuse cases and found that cases with male perpetrators and older victims were more likely to have charges laid by police, after taking into account case characteristics. However, MacMurray (1989) failed to find any significant association between cases prosecuted and the relationship between the victim and the alleged perpetrator, though this study was hampered by a small sample size. The duration of abuse (Brewer et al., 1997; Cross et al., 1994), number of types of abuse (Chapman \& Smith, 1987; Cross et al., 1994; MacMurray, 1989; Tjaden \& Thoennes, 1992), and seriousness of the abusive acts (Brewer et al., 1997; Chapman \& Smith, 1987; Tjaden \& Thoennes, 1992) have all been found to predict prosecution of cases. The presence of drugs or alcohol has also been found to influence police charging decisions by increasing the likelihood that charges will be laid (Connolly \& Read, 2007).

Prior to the 1980s, apart from sexual abuse cases, most police agencies were dismayed from getting involved in domestic violence and child 
maltreatment investigations with the notion that these are matters best handled by CPS (Bourg \& Stock, 1994). However, in the 1980s through to the 1990s, children's rights advocates and studies started providing evidence to the effect that police involvement in child maltreatment investigations can deter perpetrators (Jones, Finkelhor, \& Kopiec, 2001). Finkelhor and Jones (2006) argued that the decline in child abuse cases in the United States in the 1990s has been in part due to the aggressive charging policies, increasing presence of police activities in the community, specialized domestic violence units within the police administration charged with the mandate to intervene in child abuse cases, as well as police officers trained to investigate and prosecute sexual abuse both within and outside the family. Potential abusers may feel less confident that they could get away with child abuse if they hear about the arrests and charges of individuals who abused children (Finkelhor \& Jones, 2006). Further examination of factors associated with police charging decisions could provide additional beneficial information to improve investigation procedures (e.g., identifying key risk factors).

Given the complex nature of child maltreatment (involving various actors such as the child, parents, CPS workers, and the police), the framework of social ecological systems by Bronfenbrenner (1992) provides the most comprehensive approach to understand a host of individual and social systemic factors that could influence police charging decisions in child maltreatment investigations. In addition to individual characteristics of the child and type of maltreatment, other contextual factors including family and household environment, relationship of the perpetrator to the victim, and case characteristics each play a role in determining whether police are likely to prefer chargers during child maltreatment investigations (Holleran, Beichner, \& Spohn, 2010; Spears \& Spohn, 1997; Spohn et al., 2001). Hence, studies aimed at understanding police involvement in child maltreatment investigations should simultaneously focus on individual characteristics of the child in addition to the broader familial and social context within which the child is a part of. Yet, most of the existing studies have often focused on the individual child and sexual abuse cases with less focus on the role of other familial and contextual factors.

Additional research to better understand police charging decisions across various types of child maltreatment would be beneficial. In addition, most of the empirical studies that have examined police charging decisions in child maltreatment investigations are from the United States. Few studies have focused on Canada, which has its own provincial and territorial child welfare laws, and federal criminal laws. Thus, it is important to examine factors that influence Canadian police charging decisions, as this would provide CPS investigative workers and law enforcement with a better understanding of child maltreatment investigations and their outcomes. 


\section{Objective}

Drawing on the social ecological framework and findings from past studies, this study sought to contribute to the existing literature by examining factors including type of maltreatment and case characteristics that influence police decisions to lay charges during CPS maltreatment investigations. Based on the extant research, it was hypothesized that, police would be more likely to lay charges in cases involving female victims and older child victims; male and older perpetrators; sexual abuse cases and cases with multiple incidents of maltreatment; cases with severe harm/maltreatment; cases that would be kept open by CPS investigative workers; previously opened cases; and cases for which drugs or hazards were present in the home.

\section{Methods}

\section{Data}

This study is based on data from the Ontario Incidence Study of Reported Child Abuse and Neglect (OIS-2008). The OIS-2008 is the fourth cycle of the child abuse and neglect incidence study in Ontario. A detailed description of the OIS-2008 including the sampling procedure has been provided elsewhere (e.g., Fallon et al., 2010). In brief, the primary objective of the OIS-2008 was to provide reliable estimates of the nature and characteristics of child maltreatment cases reported to child welfare agencies in Ontario. The OIS-2008 utilized a multi-stage sampling design in selecting child welfare service areas (CWSAs) across the province of Ontario. A CWSA is a distinct child geographic area served by a child welfare agency/office. For the OIS-2008, 23 CWSAs across Ontario were randomly selected. Data were collected from CPS workers about child maltreatment investigation cases opened between October 1, 2008, and December 31, 2008 (Fallon et al., 2010). Three months was considered to be the optimum period to ensure high participation rate and good compliance with study procedure by selected agencies. Data were collected using a comprehensive three-page assessment instrument designed to gather information on various domains, such as type of maltreatment and/ or neglect investigated, source of allegation/referral, police involvement in child maltreatment investigations, level of maltreatment substantiation, physical harm, caregiver demographic characteristics, housing characteristics, child demographic characteristics, child functioning concerns, caregiver risk factors, as well as information about placement during investigations. Ethics approval for the OIS-2008 was granted by the University of Toronto Ethics Review Board.

Within the three-month period, 7,471 investigations took place. This number of cases is then weighted by applying a composite regionalization and annualization weight in order to obtain provincial and annual incidence 
estimates. The regionalization weight was computed to adjust for the sampling procedure used during the three-month data collection period and to adjust for variations in the size of sampled agencies included in data collection. The annualization weight adjusts for the number of investigations conducted by the sampled agencies during the full year (Fallon et al., 2010). All analyses are based on the weighted data.

This study is based on children younger than age 16 years (range 0 to 15), as CPS in Ontario investigates child maltreatment cases for children younger than age 16. The OIS-2008 data set contains information on 128,748 child maltreatment investigations, of which 87,025 were "investigated incident of maltreatment" and 41,723 cases were "risk only investigation." Of the 87,025 maltreatment investigations, 38,571 were substantiated. Of the 38,571 substantiated cases, 20,600 were physical abuse, sexual abuse, or neglect cases. Of the 20,600 cases of abuse and neglect, police were involved in 3,227 cases only at the investigation level, considered laying charges in 387 cases, and laid charges in 1,608 cases. Figure 1 provides a breakdown of how the sample was obtained. This study focuses only on cases in which police laid charges $(n=1,608)$ and compared them with cases in which police were involved in the investigation but laid no charges $(n=3,227)$. Likewise deletion due to missing data on some variables included in the analysis resulted in a sample size of 4,808 .

\section{Outcome variable}

The outcome variable examined in this study was decisions by police to lay charges during CPS maltreatment investigations and was measured as a binary variable. CPS investigative workers were asked to indicate the level of police involvement in a child maltreatment investigation with the following coding options "no involvement," "investigation only," "charges are being considered," and "charges have been laid." For the purposes of this study, the categories of "no police involvement" and "charges are being considered" were dropped in this analysis. The category of "investigation only" was coded as 0; whereas the category "charges have been laid" was coded as 1 .

\section{Independent variables}

The current age of the child was measured as a continuous variable in years whereas child gender was coded as a binary variable. Type of maltreatment was measured as a nominal variable based on 28 indicators into the following categories: 0 = physical abuse (e.g., hit with a hand, hit with an object, punch, kick or bite, and choking); 1 = sexual abuse (e.g., penetration, attempted penetration, oral sex, fondling, and voyeurism); and $2=$ neglect (e.g., physical neglect, medical neglect, permitting criminal behavior, failure to provide psychological treatment, and abandonment). 


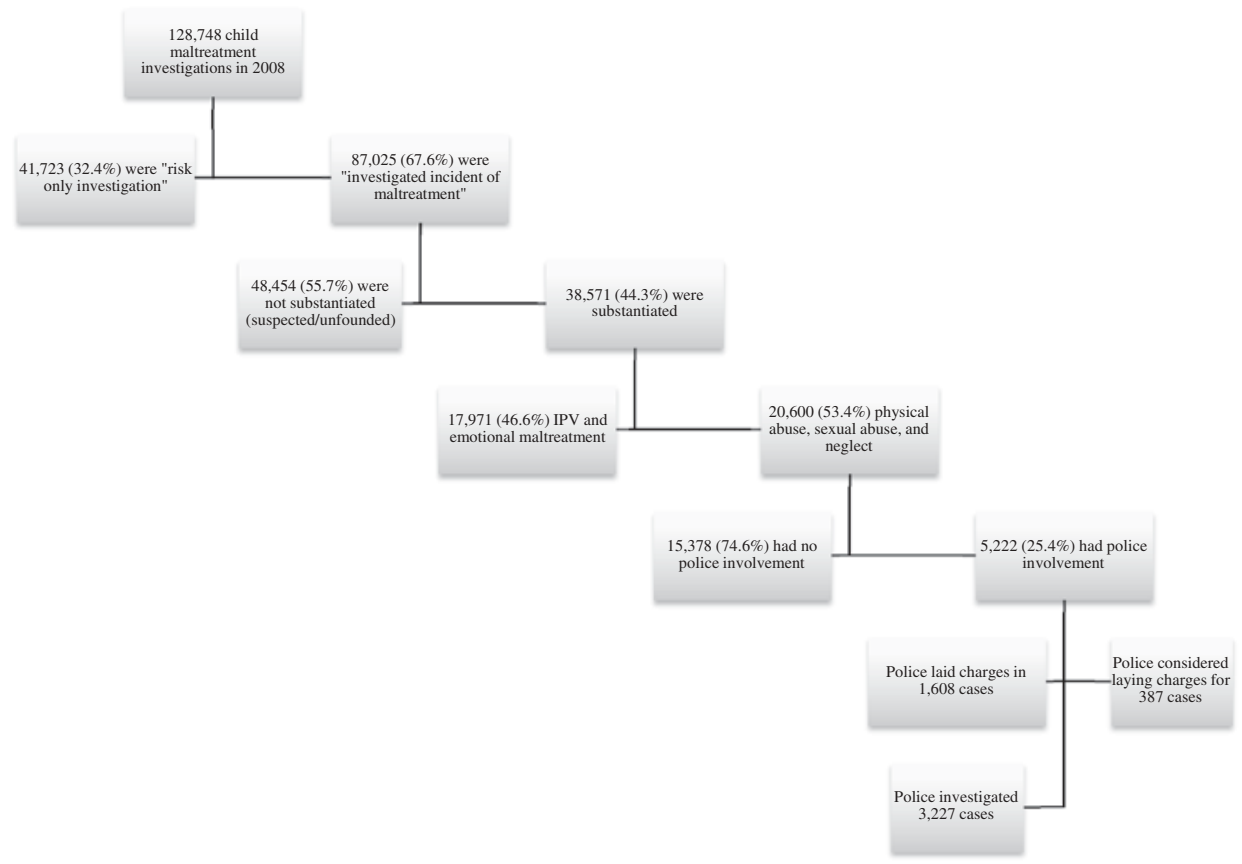

Figure 1. An illustration of how the sample was obtained from the OIS-2008. The phrase "investigated incident of maltreatment" refers to situations in which a case was investigated because of an allegation of maltreatment. The phrase "risk only investigation" refers to situations in which a case was investigated because of risk of maltreatment only (i.e., no allegation of maltreatment was made, and no specific incident of maltreatment was suspected at any point during the investigation (author information removed for review purposes).

For the purposes of this study, we excluded investigations relating to exposure to IPV and emotional abuse as police involvement in IPV investigations often tends to be as a result of the mother being the victim and not the child. CPS workers had the option of selecting up to three forms of child maltreatment. Thus, in this study, we also took into account multiple types of maltreatment with $0=$ single maltreatment versus $1=$ multiple maltreatments.

Caregiver's gender was coded as a binary variable whereas caregiver's age was measured as a nominal variable into the following categories: $0=30$ years old or less (reference category), $1=31$ to 40 years, and $2=41$ years and older. The variable "alleged perpetrator of maltreatment was caregiver" was coded as a binary variable into $0=$ no $_{\dot{\mathbf{2}}} 1=$ yes.

CPS workers were asked to indicate the caregiver's source of income. This variable was included given that the association between low family income and child maltreatment is a long-standing and consistent finding by previous studies (Drake \& Pandey, 1996). The income variable was treated as a nominal variable with the following categories: $0=$ full-time/part-time (reference category), $1=$ social assistance, and $2=$ no income. 
The variable "child lives in a house known to have drugs or household hazards" was assessed based on the presence of one of the following:

(1) accessible weapons (guns or other weapons that a child may be able to access);

(2) presence of drugs or drug paraphernalia (both legal or illegal drugs stored in such a way that a child might access and ingest them, or needles stored in such a way that a child may access them);

(3) drug production or trafficking in the home (e.g., the home has been used to grow drugs (e.g., marijuana), processed drugs (e.g., methamphetamine), or selling drugs in the home);

(4) the presence of industrial chemicals/solvent stored in a way that the child might access and ingest or touch;

(5) home injury hazards (child having access to things such as poisons, fire implements or electrical hazards); or

(6) other home health hazards (no heating, feces on the floor/walls) (Fallon et al., 2010).

Children from households that had one or more of these present were coded as 1 , whereas children from households that did not have any of the hazards present were coded as 0 .

Severity of harm/maltreatment was coded as a binary variable based on the question "whether the child's health or safety was endangered to the extent that the child could have suffered life-threatening or permanent harm (e.g., a 3-yearold child left wandering on a busy street, or a child found playing with dangerous chemicals or drugs)." In addition, this study took into account whether a case file had previously been opened and was coded as $0=$ never; $1=$ one opening; and 2 = two or more openings. Lastly, CPS investigative workers were also asked at the time of the investigation to indicate whether the case would stay open for ongoing child welfare services. Cases that remained open were coded as 1 whereas those that were closed were coded as 0 .

\section{Data analyses}

Data was analyzed in three phases. First descriptive statistics of the outcome and the independent variables were obtained with mean and standard deviation for child's age and percentage for the categorical variables. Next, bivariate association between the outcome variable and child's age was examined using one-way ANOVA. Pearson chi-square was used to test the bivariate associations between police charging decisions and the categorical independent variables. Binary logistic regression was then conducted to examine factors associated with police charging decisions. Logistic regression was chosen because the outcome variable (police charging decisions during child maltreatment investigations) was 
measured as a binary variable (no charges laid versus charges have been laid) and the independent variables were measured as both continuous and categorical variables.

Three models were built using hierarchical regression method described by Cohen et al. (2003). Child demographic variables, maltreatment type, and multiple types of maltreatment were entered in Model 1. Model 2 consists of variables in Model 1 plus caregiver demographic factors and household safety. The final model consists of variables in Model 2 plus the severity of harm/maltreatment, whether the case was previously opened, and whether the case will remain open for ongoing child welfare services. Model fitness was assessed based on the Nagelkerke pseudo R-square. The Nagelkerke pseudo R-square is the equivalent of the R-square found in ordinary least squares (OLS) regression and measures the overall proportion of variance in the outcome variable explained by all the independent variables (Tabachnick \& Fidell, 2007). In this study, variables were considered significant if the $p$-value was less than .05. All analyses were conducted using SPSS Version 21 for windows (SPSS Inc., Chicago, IL, USA).

\section{Results}

\section{Sample characteristics}

Of the estimated 4,808 child maltreatment investigations with complete data on the variables examined, police laid charges for-one-third of the cases (33.3\%). The average age of the children examined was 8.88 years $(\mathrm{SD}=4.74$; range $0-15)$. The majority of the children were female (57.6), and the majority of the caregivers were female (86.7\%). The age distribution of the caregivers was: $28.9 \%$ were age 30 years or younger, $41.2 \%$ were between 31 and 40 years, and $29.9 \%$ were 41 years and older. With respect to type of maltreatment, physical abuse (45.2\%) and neglect (43.7\%) were the most prevalent types of maltreatment investigated and the remainder (11.1\%) was related to sexual abuse cases. A little over $18 \%$ of the children experienced multiple types of maltreatment. Table 1 provides the general distribution of the variables used in this study.

\section{Bivariate results}

With the exception of child gender, significant bivariate associations were found between police charging decisions and all the independent variables. For example, the average age of children investigated for cases in which charges were laid was significantly greater than the average age of children investigated for cases in which no charges were laid ( $M_{\text {charges not laid }}=8.25$ versus $M_{\text {charges laid }}=9.15$; $F(1,4,806)=38.33, p=.001)$. The results also indicate that about $57.7 \%$ of sexual abuse cases compared to $35.8 \%$ of physical abuse cases, and $24.6 \%$ of neglect cases had charges laid $\left(\chi^{2}=220.96, \mathrm{df}=2, p<.001\right)$. More than half $(51.4 \%)$ of 
Table 1. Sample Distribution of Characteristics of the Analysis Variables (Weighted Sample $=4808$ ).

\begin{tabular}{|c|c|}
\hline Variables & Estimated \# of investigations (\%) \\
\hline \multicolumn{2}{|l|}{ Outcome variable } \\
\hline \multicolumn{2}{|l|}{ Charges laid } \\
\hline No & $3,205(66.7)$ \\
\hline Yes & $1,603(33.3)$ \\
\hline \multicolumn{2}{|l|}{ Independent variables } \\
\hline Age in years, Mean (SD) & $8.55(4.74)$ \\
\hline \multicolumn{2}{|l|}{ Child's gender } \\
\hline Male & $2,039(42.4)$ \\
\hline Female & $2,770(57.6)$ \\
\hline \multicolumn{2}{|l|}{ Caregiver's age } \\
\hline Less than 30 years & $1,388(28.9)$ \\
\hline 31 to 40 years & $1,981(41.2)$ \\
\hline 41 years and above & $1,440(29.9)$ \\
\hline \multicolumn{2}{|l|}{ Caregiver's gender } \\
\hline Female & $4,169(86.7)$ \\
\hline Male & $639(13.3)$ \\
\hline \multicolumn{2}{|l|}{ Source of caregiver's income } \\
\hline Fulltime/Part-time employment & $2,167(45.1)$ \\
\hline Social assistance & $1,580(32.9)$ \\
\hline No income & $1,062(22.1)$ \\
\hline \multicolumn{2}{|l|}{ Type of maltreatment } \\
\hline Neglect & $2,103(43.7)$ \\
\hline Physical abuse & $2,171(45.2)$ \\
\hline Sexual abuse & $534(11.1)$ \\
\hline \multicolumn{2}{|l|}{ Multiple types of maltreatment } \\
\hline No & $3,936(81.9)$ \\
\hline Yes & $872(18.1)$ \\
\hline \multicolumn{2}{|c|}{ Alleged perpetrator of maltreatment was caregiver } \\
\hline No & $1,476(30.7)$ \\
\hline Yes & $3,333(69.3)$ \\
\hline \multicolumn{2}{|c|}{ Child lives in a house known to have drugs or household hazards } \\
\hline No & $4,159(86.5)$ \\
\hline Yes & $650(13.5)$ \\
\hline \multicolumn{2}{|l|}{ Case will remain open } \\
\hline No & $2,312(48.1)$ \\
\hline Yes & $2,497(51.9)$ \\
\hline \multicolumn{2}{|l|}{ Number of previous case opening } \\
\hline No & $2,034(42.3)$ \\
\hline One & $662(13.8)$ \\
\hline Two or more times & $2,112(43.9)$ \\
\hline \multicolumn{2}{|l|}{ Severity of harm $/$ maltreatment } \\
\hline Not severe & $3,242(67.4)$ \\
\hline Severe & $1,566(32.6)$ \\
\hline
\end{tabular}

cases with multiple types of maltreatment compared to $29.3 \%$ of cases with single maltreatment had charges laid $\left(\chi^{2}=155.91, \mathrm{df}=1, p<.001\right)$. With respect to caregiver and household characteristics, we found that police were more likely to lay charges if the caregiver was older, male, had no income, or was not alleged as the perpetrator of the maltreatment. The proportion of children who lived in houses with drugs or hazardous materials and had charges laid $(52.2 \%)$ was significantly greater than the proportion of children who lived in safe houses that had charges laid (30.4) $\left(\chi^{2}=119.70, \mathrm{df}=1, p<.001\right)$. We also found that police 
Q2 Table 2. Bivariate Association Between Police Charging Decisions and Independent Variables.

\begin{tabular}{|c|c|c|c|}
\hline \multirow[b]{2}{*}{ Variables } & \multicolumn{2}{|c|}{ Charges laid } & \multirow[b]{2}{*}{ Test (sig.) } \\
\hline & No n (\%) & Yes n (\%) & \\
\hline Child's age - Mean (SD) & $8.25(4.54)$ & $9.15(5.06)$ & $F=38.33(.001)$ \\
\hline Child's gender & & & $\chi^{2}=1.82(.177)$ \\
\hline Male & $1,381(67.7)$ & $658(32.3)$ & \\
\hline Female & $1,824(65.9)$ & $945(34.1)$ & \\
\hline Caregiver's age & & & $\chi^{2}=41.42(.001)$ \\
\hline Less than 30 years & $979(70.5)$ & $409(29.5)$ & \\
\hline 31 to 40 years & $1,362(68.8)$ & $619(31.2)$ & \\
\hline 41 years and above & $865(60.1)$ & $575(39.9)$ & \\
\hline Caregiver's gender & & & $\chi^{2}=44.42(.001)$ \\
\hline Female & $2,853(68.4)$ & 1316 (31.6) & \\
\hline Male & $352(55.1)$ & $287(44.9)$ & \\
\hline Source of caregiver's income & & & $\chi^{2}=57.52(.001)$ \\
\hline Fulltime/Part-time employment & $1,484(68.5)$ & $683(31.5)$ & \\
\hline Social assistance & $1,115(70.6)$ & $464(29.4)$ & \\
\hline No income & $607(57.2)$ & $455(42.8)$ & \\
\hline Type of maltreatment & & & $\chi 2=220.96(.001)$ \\
\hline Neglect & $1,586(75.4)$ & $517(24.6)$ & \\
\hline Physical abuse & $1,393(64.2)$ & $778(35.8)$ & \\
\hline Sexual abuse & $226(42.3)$ & $308(57.7)$ & \\
\hline Multiple types of maltreatment & & & $\chi 2=155.91(.001)$ \\
\hline No & $2,781(70.7)$ & $1,155(29.3)$ & \\
\hline Yes & $424(48.6)$ & $448(51.4)$ & \\
\hline Alleged perpetrator of maltreatment was caregiver & & & $\chi 2=212.91(.001)$ \\
\hline No & $764(51.8)$ & $712(48.2)$ & \\
\hline Yes & $2,442(73.3)$ & $891(26.7)$ & \\
\hline $\begin{array}{l}\text { Child lives in a house known to have drugs or household } \\
\text { hazards }\end{array}$ & & & $\chi^{2}=119.70(.001)$ \\
\hline No & 2,894 (69.6) & $1264(30.4)$ & \\
\hline Yes & $311(47.8)$ & $339(52.2)$ & \\
\hline Case will remain open & & & $\chi 2=224.71(.001)$ \\
\hline No & $1,786(77.2)$ & $526(22.8)$ & \\
\hline Yes & $1,419(56.9)$ & $1,077(43.1)$ & \\
\hline Case was previously opened & & & $\chi^{2}=26.67(.001)$ \\
\hline No & $1,418(69.7)$ & $616(30.3)$ & \\
\hline One & $390(58.9)$ & $272(41.1)$ & \\
\hline Two or more times & $1,397(66.1)$ & $715(33.9)$ & \\
\hline Severity of harm/maltreatment & & & $\chi 2=131.83(.001)$ \\
\hline Not severe & 2,337 (72.1) & $905(27.9)$ & \\
\hline Severe & $868(55.4)$ & $698(44.6)$ & \\
\hline
\end{tabular}

were more likely to lay charges for cases in which the child suffered severe harm/ maltreatment, in cases that had multiple openings, or in cases that remained open for ongoing child welfare services.

\section{Multivariate results}

Table 3 shows the multivariate results from the logistic regression model predicting police charging decisions during child maltreatment investigations, while controlling for the net effect of all the other independent variables. In Model 1, both child age and gender were not significantly associated with police charging decisions. However, controlling for all other factors in 
Table 3. Logistic Regression Predicting Charging Decisions.

\begin{tabular}{|c|c|c|c|c|c|c|c|c|c|}
\hline \multirow[b]{2}{*}{ Variables } & \multicolumn{3}{|c|}{ Model } & \multicolumn{3}{|c|}{ Model 2} & \multicolumn{3}{|c|}{ Final Model } \\
\hline & AOR & Sig. & $95 \% \mathrm{Cl}$ & AOR & Sig. & $95 \% \mathrm{Cl}$ & AOR & Sig. & $95 \% \mathrm{Cl}$ \\
\hline \multicolumn{10}{|l|}{$\begin{array}{l}\text { Child demographic and } \\
\text { maltreatment types }\end{array}$} \\
\hline Child's age & 1.01 & .410 & $0.99-1.02$ & 1.03 & .001 & $1.01-1.05$ & 1.05 & .001 & $1.03-1.07$ \\
\hline \multicolumn{10}{|l|}{ Child's gender (Male) } \\
\hline Female & 0.90 & .130 & $0.79-1.30$ & 0.98 & .825 & $0.85-1.14$ & 1.12 & .129 & $0.97-1.31$ \\
\hline \multicolumn{10}{|l|}{$\begin{array}{l}\text { Type of maltreatment } \\
\text { (Neglect) }\end{array}$} \\
\hline Physical abuse & 1.53 & .001 & $1.33-1.76$ & 1.51 & .001 & $1.27-1.79$ & 1.93 & .001 & $1.60-2.32$ \\
\hline Sexual abuse & 3.76 & .001 & $3.03-4.66$ & 2.68 & .001 & $2.02-3.55$ & 3.37 & .001 & $2.50-4.55$ \\
\hline \multicolumn{10}{|l|}{$\begin{array}{l}\text { Multiple types of } \\
\text { maltreatment (No) }\end{array}$} \\
\hline Yes & 2.18 & .001 & $1.87-2.55$ & 1.79 & .001 & $1.51-2.13$ & 1.43 & .001 & $1.19-1.71$ \\
\hline \multicolumn{10}{|l|}{$\begin{array}{l}\text { Caregiver and household } \\
\text { characteristics }\end{array}$} \\
\hline \multicolumn{10}{|c|}{$\begin{array}{l}\text { Caregiver's age (Less than } 30 \\
\text { years) }\end{array}$} \\
\hline 31 to 40 years & & & & 0.72 & .002 & $0.58-0.88$ & 0.81 & .063 & $0.66-1.01$ \\
\hline 41 years and above & & & & 1.30 & .033 & $1.02-1.66$ & 1.42 & .007 & $1.10-1.82$ \\
\hline \multicolumn{10}{|l|}{ Caregiver's gender (Female) } \\
\hline Male & & & & 1.68 & .001 & $1.37-2.06$ & 1.32 & .010 & $1.07-1.62$ \\
\hline \multicolumn{10}{|c|}{$\begin{array}{l}\text { Alleged perpetrator of } \\
\text { maltreatment was caregiver } \\
\text { (No) }\end{array}$} \\
\hline Yes & & & & 0.38 & .001 & $0.32-0.45$ & 0.33 & .001 & $0.27--0.39$ \\
\hline \multicolumn{10}{|c|}{$\begin{array}{l}\text { Source of caregiver's income } \\
\text { (Full-time Part-time } \\
\text { employment) }\end{array}$} \\
\hline Social assistance & & & & 1.24 & .010 & $1.05-1.46$ & 0.95 & .539 & $0.79-1.13$ \\
\hline No income & & & & 2.48 & .001 & $2.06-2.98$ & 2.07 & .001 & $1.70-2.52$ \\
\hline \multicolumn{10}{|c|}{$\begin{array}{l}\text { Child lives in a house known } \\
\text { to have drugs or household } \\
\text { hazards (No) }\end{array}$} \\
\hline Yes & & & & 4.60 & .001 & $3.72-5.68$ & 2.16 & .001 & $1.71-2.73$ \\
\hline \multicolumn{10}{|l|}{ Case characteristics } \\
\hline \multicolumn{10}{|l|}{ Case will stay open (No) } \\
\hline Yes & & & & & & & 2.83 & .001 & $2.42-3.31$ \\
\hline \multicolumn{10}{|c|}{$\begin{array}{l}\text { Case was previously opened } \\
\text { (None) }\end{array}$} \\
\hline One & & & & & & & 1.95 & .001 & $1.57-2.43$ \\
\hline Two or more times & & & & & & & 1.42 & .001 & $1.21-1.67$ \\
\hline \multicolumn{10}{|l|}{$\begin{array}{l}\text { Severity of harm/ } \\
\text { maltreatment } \\
\text { Not severe }\end{array}$} \\
\hline Severe & & & & & & & 2.44 & .001 & $2.03-2.94$ \\
\hline $\begin{array}{l}\text { Nagelkerke pseudo R } \\
\text { square }\end{array}$ & & & .089 & & & .204 & & & .281 \\
\hline $\begin{array}{l}\text { Change in Nagelkerke } \\
\text { pseudo R square }\end{array}$ & & & & & & .115 & & & .077 \\
\hline $\begin{array}{l}\text { Percentage correctly } \\
\text { classified }\end{array}$ & & & 63.9 & & & 70.1 & & & 68.1 \\
\hline
\end{tabular}

Note AOR = adjusted odds ratio. 
Model 3, for each increase in child age by one year, the odds of police laying charges were predicted to increase by a factor of $5 \%(\mathrm{AOR}=1.05, p<.001$, $95 \% \mathrm{CI}=1.03-1.07)$. This change in significance for child age could be attributed to the reduction in standard error with the addition of caregiver demographic factors and household safety in Model 2 and maltreatment case characteristics in Model 3.

In Model 1, the odds of police laying charges in cases investigated for physical abuse were 1.53 times greater $(\mathrm{AOR}=1.53, p<.001,95 \% \mathrm{CI}=1.33-1.76)$ and 3.76 times greater for cases investigated for sexual abuse $(\mathrm{AOR}=3.76, p<.001$, $95 \% \mathrm{CI}=3.03-4.66)$ both when compared to neglect cases. This significant effect was partially attenuated with the addition of variables in Models 2 and 3. In Model 3, the odds of police laying charges were 1.93 times greater for physical abuse cases ( $\mathrm{AOR}=1.93, p<.001,95 \% \mathrm{CI}=1.60-2.32)$ and 3.37 times greater for sexual abuse cases $(\mathrm{AOR}=3.37, p<.001,95 \% \mathrm{CI}=2.50-4.55)$. Controlling for all other factors in Model 3, the odds were 1.43 times higher for police to lay charges in cases involving multiple types of maltreatment when compared to cases involving single maltreatment $(\mathrm{AOR}=1.43, p<.001,95 \% \mathrm{CI}=1.19-1.71)$. In Model 3, the odds of police laying charges were significantly greater in instances where the perpetrator was 41 years of age and older, male, or not the caregiver.

The source of caregiver income was also significantly associated with police charging decisions such that odds were more than two times higher for police to lay charges in cases where the caregiver had no income compared to cases in which the caregiver's source of income was from full-time/part-time work $(\mathrm{AOR}=2.07 p<.001,95 \% \mathrm{CI}=1.70-2.52)$. Police were also more likely to lay charges if: the child who was maltreated lives in a house with drugs or hazardous materials, the abuse or maltreatment suffered by the child was severe, or the case had previously been opened. Lastly, odds of police laying charges were 2.83 times greater in cases that remained open for ongoing child welfare services versus closed cases $(\mathrm{AOR}=2.83, p<.001,95 \% \mathrm{CI}=2.42-3.31)$.

Based on the Nagelkerke pseudo R square, all the variables entered in Model 1 explained $8.9 \%$ of the variance in police charging decisions. Adding caregiver demographic factors and household safety in Model 2 saw an improvement in this number from $8.9 \%$ to $20.4 \%$. In Model 3, all the independent variables explained $28.1 \%$ of the variance in charging decisions. This suggests that each block of variables contributed to the fitness of the model.

\section{Discussion}

The objective of this study was to address a gap in the literature and examine factors impacting police decisions to lay charges during child maltreatment investigations in Ontario. In Ontario, police were involved in $25 \%$ of all substantiated child maltreatment cases. Thus, the child welfare and law 
enforcement systems work together on a sizable minority of child welfare cases. We found that the proportion of cases where police decided to lay changes was lower than the proportions identified in previous studies that were conducted in the 21st century. Charges were laid in about one-third of substantiated maltreatment investigations in which police were involved, versus about two-thirds of cases in previous literature (Faller \& Henry, 2000; Walsh et al., 2010). However, these studies examined sexual abuse investigations specifically, while the current study examined child maltreatment cases more broadly. Police laid charges more frequently in sexual abuse investigations than in other types of child maltreatment cases (Hartley et al., 2013).

The following factors significantly explained police charging decisions: older age, cases investigated for sexual abuse, cases with multiple types of maltreatment and severe harm/maltreatment, cases that were previously opened and open for ongoing child welfare services, and cases where the child is living in a house known to have drugs or household hazards. Police were also more likely to lay charges if the caregiver was 41 years and older and male, and if the alleged perpetrator was not the caregiver.

Consistent with previous research (Brewer et al., 1997; Finkelhor, 1983; Stroud et al., 2000; Tjaden \& Thoennes, 1992; Walsh et al., 2010), cases with older child victims were more likely to have their cases prosecuted. Interestingly, child age only significantly predicted police laying charges when caregiver and household characteristics were included in the model and remained significant when case characteristics were added in the final model. Thus, it appears that child age alone may not be predictive of police charging decisions. Perhaps, caregiver characteristics such as age, income, relationship to the child, household safety concern as well as severity of harm and history of maltreatment offer some additional insights into the relationship between child age and charging decisions. The fact that whether or not age is a significant predictor in the model is dependent on the other variables in the model may explain the somewhat inconsistent findings related to age and case prosecution in previous literature (Brewer et al., 1997; MacMurray, 1989; Sedlak et al., 1996).

Similar to a recent study by Hartley et al. (2013), this study found that police were more likely to lay charges in physical and sexual abuse cases relative to neglect cases. The extant literature has consistently found that police charging decisions are higher for sexual abuse cases (Brewer et al., 1997; Bryden \& Lengnick, 1997; Cross et al., 2005, 2015; Sedlak et al., 2005; Walsh et al., 2010). This finding may be because child sexual abuse includes using children younger than age 16 years for all types of sexual activity, from sexual touching to prostitution. However, defining physical abuse and neglect that is punishable by law is more difficult. There is more room for clinical judgment on whether the severity of the maltreatment is sufficient to warrant the decision to lay charges (Government of Ontario, 1990; Ontario Association of Children's Aid Societies, 2015). 
The results of this study also lend support to earlier studies suggesting that police are more likely to lay charges if the harm or maltreatment suffered by the child is severe or results in injury (Brewer et al., 1997; Cross et al., 1994, Jones et al., 2006; Sedlak et al., 2005; Stroud et al., 2000). It has been stated that police lay charges only in cases where there is a high probability of securing a conviction to avoid making wrongful prosecutions (Holleran et al., 2010). Sexual and physical abuse cases that are severe may provide more physical evidence of maltreatment than neglect cases (Ontario Association of Children's Aid Societies, 2015); thus supporting the notion that police tend to lay charges only in cases where evidence of maltreatment is clear. Also supporting this notion is the fact that cases with multiple types of maltreatment, previously opened cases, and cases that are already receiving child welfare services were more likely to result in charges being laid. If present, these factors provide police with additional reliable evidence of maltreatment and increase the likelihood of the case being charged.

Similar to previous studies, this study found significant associations between police charging decisions and caregiver and household characteristics (Connolly \& Read, 2007; Walsh et al., 2010). In particular, cases with older and male caregivers were more likely to be charged. When the caregiver was female, charges were less likely to be laid. This finding may be due to the fact that perpetrators of maltreatment, particularly sexual abuse, are more likely to be male (Tyler \& Cauce, 2002; Walsh et al, 2010).

Consistent with previous research (Brewer et al., 1997; Chapman \& Smith, 1987; Cross et al., 1994; Finkelhor, 1983; Pipe et al., 2013; Tjaden \& Thoennes, 1992), a negative association was found between caregiver as the alleged perpetrator and police decisions to lay charges. It is a common finding that victims generally know their maltreatment offenders; however, the perpetrator is not always the caregiver. For sexual abuse in particular, it has been found that in about one-quarter of cases a family member maltreats the child, and someone the child knows in his or her social network maltreats the child in $60 \%$ of cases. Only in $14 \%$ of cases are children abused by someone who is unfamiliar to them (Finkelhor, 2009). Thus, the perpetrator of abuse is most commonly not the caregiver but is still familiar to the child. However, several studies have found that police are alse-less likely to lay charges if the victim knew the alleged perpetrator (Hershkowitz et al., 2007; Pipe et al., 2007). This finding is concerning in that the child may be at heightened risk of future abuse and maltreatment in these cases given that they may have frequent contact with the perpetrator within their social network.

One potential explanation for this negative association is that some children may feel less inclined to provide information or deny that they were abused to protect the image of their familiar perpetrator, whether that is their caregiver or another individual within their social network (Brewer et al., 1997; 
Pipe et al., 2013). In support of this theory, Hershkowitz et al. (2007) found that the proportion of uninformative responses such as "don't know," and "don't remember" provided by children who were abused by their caregivers was significantly greater than the proportion of uninformative responses provided by children who were abused by alleged perpetrators who were not their caregivers. Therefore, there is the need for the development of strategic and effective interviewing techniques that take into account the sensitive nature of the abuse experienced by these children and the difficulty involved in reporting abuse when the perpetrator is familiar. Future research should also further examine the association between the specific relationship of the perpetrator to the victim (e.g., caregiver, step-parent, family friend) and police decisions to lay charges in order to obtain a clearer picture on the link between the relationship between-the perpetrator and victim and police proceedings. This research would help identify whether further training on the common characteristics of perpetrators of child maltreatment for those involved in making prosecution charges is needed.

In regards to household factors, homes with drugs and hazardous materials were more likely to be prosecuted. This finding suggests that, in Ontario, police decisions to lay charges are appropriate in that they respond to law violations. Drug use and possession are illegal so prosecution rates are expected to increase with the presence of drugs and dangerous home environments.

\section{Study limitations}

This study has some limitations that must be taken into account when interpreting the findings. First, this study is correlational so a causal link between the independent variables and the outcome variable could not be identified. Second, this study only examined cases opened in the CPS for a short time period, limiting the generalizability of the data. Future research should examine cases involving a larger time frame and also involve follow-up assessments on cases to provide more information on police decisions to lay charges in child maltreatment situations and the long-term impact of these decisions on the child, family, and community. Given that the sample examined was primarily Caucasian, this study did not examine race/ethnicity, which may have impacted the results. Previous research has consistently found that minority groups are more likely to be arrested, charged, and prosecuted by police (Crutchfield et al., 2012). This racial disparity may also influence police decisions in child maltreatment situations and would be beneficial to include in future research examining police decisions to lay charges in CPS cases.

Lastly, although this study examined police decision to lay charges in known child maltreatment cases, it is important to mention that relying on official records often understates the problem of child maltreatment (Finkelhor, 2005). The OIS-2008 is limited to reports investigated by child 
welfare agencies and does not include reports that were screened out, cases that were only investigated by the police, and cases that were never reported (Fallon et al., 2010).

\section{Implications and future research directions}

Charging decisions by police tend to be influenced by a host of factors beyond the legal characteristics of the case. The findings of the current study are promising in that they are consistent with police policy in Ontario that charges should only be laid in cases where there are reasonable or probable grounds that a crime occurred (i.e., evidence of other crimes such as drugs, severity of maltreatment, and cases already receiving services). In addition, factors such as victims age and suspects gender found to be associated with police charging decisions are consistent with those identified in the American literature (Pipe et al., 2013). Similar to the extant research, the current study identified that police charging decisions are largely driven by sexual and physical abuse cases; the severity of harm/maltreatment suffered by the child; evidence of previous family difficulties; male, non-caregiver perpetrators; and family financial resources and household safety. Overall, these findings suggest that police lay charges in situations for which supporting evidence is sufficient to identify an illegal activity. However, these findings also indicate that more weight may be placed on some factors than others (e.g., previous CPS involvement and the type of maltreatment). For example, if previous CPS involvement is heavily weighted, it is possible that some cases without previous CPS involvement may be overlooked when charges should be laid and some cases with previous CPS involvement may be wrongfully penalized.

It will be important for future research to examine the impact of police decisions on the victim and perpetrator and determine whether distinguishing cases based on the key factors identified in this study (i.e., type and severity of maltreatment, previous involvement with the CPS, caregiver and household factors) is an effective approach to identifying crimes related to child maltreatment and preventing further harm to a child. One way to examine this would be to follow child maltreatment cases in a longitudinal study to examine the decision-making process to lay charges and the outcomes of cases following police decisions to lay or not lay charges. For example, for cases with police involvement where charges are not laid initially, do the child/family experience additional harm or do they have police involvement in the future that does result in charges being made? Also, do police decisions to lay charges impact the occurrence of future child maltreatment?

Lastly, some of the current findings, especially the negative association between caregiver as the alleged perpetrator and police charging decisions, as well as neglect and police charging decisions, merit further exploration. More information on the specific relationship between the child and the perpetrator and its association with prosecution decisions may be helpful. The current 
findings suggest that police decisions to lay charges for maltreatment are conservative and most often made in cases where there is clear and ample evidence. However, severe maltreatment, such as neglect, may not always be clearly visible but can have detrimental long-term effects on child development (Grayson, Childress, Ernst, \& Webb, 2006; Perry, 2002). The safety of children in maltreatment investigations is paramount so potential situations that prevent the accumulation of evidence or accurate accounts of child maltreatment may require unique or creative methods of evidence gathering. Additional training for police and CPS workers may also be beneficial to improve their ability to identify more subtle signs of illegal caregiver practices. It would also be important for future research to examine what measures are taken to protect the children from further maltreatment when maltreatment and/or an illegal activity is suspected but sufficient evidence is not obtained. This focus is especially imperative for instances where a child may continue to experience maltreatment from the caregiver or an individual within their social network.

\section{References}

Bourg, S., \& Stock, H. V. (1994). A review of domestic violence arrest statistics in a police department using a pro-arrest policy: Are pro-arrest policies enough? Journal of Family Violence, 9(2), 177-189.

Brewer, K. D., Rowe, D. M., \& Brewer, D. D. (1997). Factors related to prosecution of child sexual abuse cases. Journal of Child Sexual Abuse, 6(1), 91-111.

Bronfenbrenner, U. (1992). Ecology systems theory. In R. Vasta (Ed.), Six theories of child development: Revised formulations and current issues (pp.187-249). London: Jessica Kingsley.

Browne, D. T., Verticchio, D., Shlonsky, A., Thabane, L., Hoch, J., \& Byrne, C. (2010). The family standpoint of investigation: Examining the correlates and costs of parental stress in a sample of families involved with Ontario child welfare. Canadian Journal of Community Mental Health, 29(2), 131-154.

Bryden, D. P., \& Lengnick, S. (1997). Rape in the criminal justice system. Journal of Criminal Law and Criminology, 87(4), 1194-1384.

Chapman, J. R., \& Smith, B. (1987). Response of social service and criminal justice agencies to child sexual complaints. Response, 10, 7-13.

Cohen J., Cohen P., West, S., Aiken L.S. (2003). Applied multiple regression/correlation analysis for the behavioral sciences. London: Lawrence Erlbaum Associates.

Community Legal Education Ontario (CLEO). (2013). Do you know a woman who is being abused? A legal rights handbook. Toronto, Ontario, Canada: CLEO. http://yourlegalrights. on.ca/resource/do-you-know-woman-who-being-abused-legal-rights-handbook?tid_ref=1

Connolly, D. A., \& Read, J. D. (2007). Canadian criminal court reports of historic child sexual abuse: Factors associated with delayed prosecution and reported repression. In M.-E. Pipe, M. E. Lamb, Y. Orbach, \& A.-C. Cederborg (Eds.), Child sexual abuse: Disclosure, delay and denial (pp. 195-216). Mahwah, NJ: Lawrence Erlbaum Associates.

Cross, T. P., Chuang, E., Helton, J. J., \& Lux, E. A. (2015). Criminal Investigations in Child Protective Services Cases An Empirical Analysis. Child Maltreatment, 20(2), 104-114.

\section{(1)}


Cross, T. P., Finekelhor, D., \& Ormrod, R. (2005). Police involvement in child protective services investigations: Literature review and secondary data analysis. Child Maltreatment, 10(3), 224-244.

Crutchfield, R. D., Skinner, M. L., Haggerty, K. P., McGlynn, A., \& Catalano, R. F. (2012). Racial disparity in police contacts. Race and Justice, 2(3), 179-202.

Drake, B., \& Pandey, S. (1996). Understanding the relationship between neighborhood poverty and specific types of child maltreatment. Child Abuse \& Neglect, 20(11), 1003-1018.

Faller, K. C., \& Henry, J. (2000). Child sexual abuse: A case study in community collaboration. Child Abuse \& Neglect, 24(9), 1215-1225.

Fallon, B., Trocmé, N., MacLaurin, B., Sinha, V., Black, T., Felstiner, C., ... \& Johnston, A. (2010). Ontario Incidence Study of Reported Child Abuse and Neglect-2008 (OIS-2008). Toronto, Ontario, Canada: Child Welfare Research Portal.

Finkelhor, D. (1983). Removing the child-prosecuting the offender in cases of sexual abuse: Evidence from the national reporting system for child abuse and neglect. Child Abuse \& Neglect, 7, 195-205.

Finkelhor, D. (2005). The main problem is underreporting child abuse and neglect. In D. R. Loseke, R. J. Gelles, \& M. M. Cavanaugh (Eds.), Current controversies on family violence ( $2^{\text {nd }}$ ed., pp. 299-310). Thousand Oaks, CA: Sage Publications.

Finkelhor, D. (2009). The prevention of childhood sexual abuse. The Future of Children, 19(2), 169-194.

Finkelhor, D., \& Jones, L. (2006). Why have child maltreatment and child victimization declined? Journal of Social Issues, 62(4), 685-716.

Government of Ontario. (1990). Child and Family Services Act. <http://www.elaws.gov.on.ca/ html/statutes/english/elaws_statutes_90c11_e.htm>

Grayson, J., Childress, A., Ernst, W., \& Webb, N. (2006). Maltreatment and its effects on early brain development. Virginia Child Protection Newsletter, 77, 1-16.

Hartley, D. J., Mullings, J. L., \& Marquart, J. W. (2013). Factors impacting prosecution of child sexual abuse, physical abuse, and neglect cases processed through a children's advocacy center. Journal of Child and Adolescent Trauma, 6(4), 260-273.

Hershkowitz, I., Horowitz, D., \& Lamb, M. E. (2007). Individual and family variables associated with disclosure and non-disclosure of child abuse in Israel. In M.-E. Pipe, M. E. Lamb, Y. Orbach, \& A.-C. Cederborg (Eds.). Child sexual abuse: Disclosure, delay and denial (pp. 63-76). Mahwah, NJ: Erlbaum.

Holleran, D., Beichner, D., \& Spohn, C. (2010). Examining charging agreement between police and prosecutors in rape cases. Crime and Delinquency, 56(3), 385-413.

Jones, L. M., Finkelhor, D., \& Halter, S. (2006). Child maltreatment trends in the 1990s: Why does neglect differ from sexual and physical abuse? Child Maltreatment, 11(2), 107-120.

Jones, L. M., Finkelhor, D., \& Kopiec, K. (2001). Why is sexual abuse declining? A survey of state child protection administrators. Child Abuse \& Neglect, 25(9), 1139-1158.

MacMurray, B. K. (1989). Criminal determination of child sexual abuse: Prosecutor casescreening judgments. Journal of Interpersonal Violence, 4(2), 233-244.

Ontario Association of Children's Aid Societies (2015). What is abuse? <http://www.oacas. org/childrens-aid-child-protection/what-is-abuse/>

Paine, M. L., \& Hansen, D. J. (2002). Factors influencing children to self-disclose sexual abuse. Clinical Psychology Review, 22, 271-295.

Perry, B. D. (2002). Childhood experience and the expression of genetic potential: What childhood neglect tells us about nature and nurture. Brain and Mind, 3, 79-100.

Pipe, M.-E., Orbach, Y., Lamb, M. E., Abbott, C. B., \& Stewart, H. (2013). Do case outcomes change when investigative interviewing practices change? Psychology, Public Policy, and Law, 19(2), 179-190. 
Pipe, M.-E., Sternberg, K., Lamb, M. E., Orbach, Y., Stewart, H., \& Esplin, P. (2007). Factors associated with non-disclosures of suspected abuse during forensic interviews. In M.-E. Pipe, M. E. Lamb, Y. Orbach, \& A-C Cederborg (Eds.), Child sexual abuse: Disclosure, delay and denial (pp. 77-96). Mahwah, NJ: Erlbaum.

Sedlak, A. J., Doucek, H. J., Lyons, P., Wells, S. J., Schultz, D., \& Gragg, F. (2005). Child maltreatment and the justice system: Predictors of court involvement. Research on Social Work Practice, 15(5), 389-403.

Sedlak, A. J., Gragg, F., Schultz, D. J., \& Wells, S. J. (1996). Detailed case tracking in a local jurisdiction. In Davis, N.S. \& Wells, S.J. (Eds.), Justice system processing of child abuse and neglect cases. Washington, DC: American Bar Association Center on Children and the Law.

Spears, J. W., \& Spohn, C. C. (1997). The effect of evidence factors and victim characteristics on prosecutors' charging decisions in sexual assault cases. Justice Quarterly, 14(3), 501-524.

Spohn, C., Beichner, D., \& Davis-Frenzel, E. (2001). Prosecutorial justifications for sexual assault case rejection: Guarding the "Gateway to Justice". Social Problems, 48(2), 206-235.

Stroud, D. D., Martens, S. L., \& Barker, J. (2000). Criminal investigation of child sexual abuse: A comparison of cases referred to the prosecutor to those not referred. Child Abuse \& Neglect, 24(5), 689-700.

Tabachnick, B. G., \& Fidell, L. S. (2007). Using multivariate statistics. Boston, MA: Allyn and Bacon.

Tjaden, P. G., \& Thoennes, N. (1992). Predictors of legal intervention in child maltreatment cases. Child Abuse \& Neglect, 16, 807-821.

Tyler, K., \& Cauce, A. M. (2002). Perpetrators of early physical and sexual abuse among homeless and runaway adolescents. Child Abuse \& Neglect, 26(12), 1261-1274.

Walsh, W. A., Jones, L. M., Cross, T. P., \& Lippert, T. (2010). Prosecuting child sexual abuse: The importance of evidence type. Crime and Delinquency, 56(3), 436-454. 